Article

\title{
An in Vitro Study on the Effect of Combined Treatment with Photodynamic and Chemical Therapies on Candida albicans
}

\author{
Yi-Hsuan Hsieh ${ }^{1}$, Jun-Hui Zhang ${ }^{2}$, Wen-Ching Chuang ${ }^{2}$, Kun-Hua Yu ${ }^{2}$, Xian-Bin Huang ${ }^{2}$, \\ Yao-Chang Lee ${ }^{3}$ (iD and Cheng-I Lee ${ }^{2, *}$ \\ 1 Department of Clinical Pathology, Buddhist Dalin Tzu Chi General Hospital, Chia-Yi 62247, Taiwan; \\ dm989587@tzuchi.com.tw \\ 2 Department of Biomedical Sciences, National Chung Cheng University, Min-Hsiung, Chia-Yi 62102, Taiwan; \\ s0994757@gmail.com (J.-H.Z.); danny7910791@gmail.com (W.-C.C.); ykhuna@gmail.com (K.-H.Y.); \\ loveghate43@gmail.com (X.-B.H.) \\ 3 National Synchrotron Radiation Research Center, Hsinchu 30076, Taiwan; yclee@nsrrc.org.tw \\ * Correspondence: biocil@ccu.edu.tw; Tel.: +886-5-2729-157
}

Received: 13 December 2017; Accepted: 18 January 2018; Published: 24 January 2018

\begin{abstract}
Candida albicans is the most commonly encountered human fungal pathogen, and it is traditionally treated with antimicrobial chemical agents. The antimicrobial effect of these agents is largely weakened by drug resistance and biofilm-associated virulence. Enhancement of the antimicrobial activity of existing agents is needed for effective candidiasis treatment. Our aim was to develop a therapy that combined biofilm disruption with existing antimicrobial agents. Photodynamic therapy (PDT) utilizing curcumin and blue light was tested as an independent therapy and in combination with fluconazole treatment. Viability assays and morphology analysis were used to assess the effectiveness of $C$. albicans treatment. Results showed that fluconazole treatment decreased the viability of planktonic $C$. albicans, but the decrease was not as pronounced in adherent C. albicans because its biofilm form was markedly more resistant to the antimicrobiotic. PDT effectively eradicated C. albicans biofilms, and when combined with fluconazole, PDT significantly inhibited C. albicans to a greater extent. This study suggests that the addition of PDT to fluconazole to treat C. albicans infection enhances its effectiveness and can potentially be used clinically.
\end{abstract}

Keywords: photodynamic therapy; Candida albicans; curcumin; fluconazole; biofilm

\section{Introduction}

Photodynamic therapy (PDT) is a minimally invasive therapy approved for the treatment of cancers [1] and other diseases [2]. PDT requires light at a specific wavelength to raise the electrons in photosensitizer (PS) molecules to the excited singlet state. The excited PS may cross to the triplet state-with slightly lower energy - by undergoing an intersystem crossing process. Further photochemical reaction runs along the type I or type II pathway. Along the former pathway, the triplet state PS transfers electrons to nearby molecules to produce free radicals. Along the latter pathway, it transfers energy to nearby ground-state (triplet-state) molecular oxygen to produce excited oxygen in the singlet state (singlet oxygen; ${ }^{1} \mathrm{O}_{2}$ ). Both free radicals and singlet oxygen generated through the type I and type II pathways are cytotoxic.

Candida albicans is the most commonly encountered human fungal pathogen [3], and is an important opportunistic pathogen-especially in intensive care units [4] and oral infections [5]. C. albicans is a polymorphic fungus growing either as a unicellular budding yeast or in filamentous form including pseudohyphae and true hyphae. Pseudohyphal growth is a transition between budding 
and hyphal growth, and the transition is essential to virulence [6]. Traditionally, C. albicans infection is treated with antifungal agents such as intravenous amphotericin $\mathrm{B}$, oral fluconazole, and topical clotrimazole [7]. However, the effect of antifungal agents is greatly weakened by the drug resistance ascribed to hyphal and pseudohyphal secretion of extracellular matrix from biofilms [8,9]. Moreover, fluconazole has various side effects [10-13]. Hence, alternative treatments against candidiasis are being considered [14]. For the easy access of visible light to the oral cavity, phototherapies can be applied to oral candidiasis, such as burning mouth syndrome $[15,16]$. From the small scale of clinical trials, phototherapy seemed to be effective in decreasing plaque size, but complete eradication of fungal pathogens is expected. In the past, antimicrobial PDTs [2,17] have included rose bengal PDT [18] and 5-aminolevulinic acid (5-ALA) PDT [19] against C. albicans. However, micromolar concentrations of rose bengal can cause damage, for example, to the living human corneal epithelium [20]. In humans, 5-ALA is converted to protoporphyrin IX, the photosensitizer. Typically, millimolar concentrations of 5-ALA are required to be effective. To avoid toxicity of photosensitizers and treat candidiasis efficiently, further development of anti-microbial PDTs and multi-antibiotic approaches are required.

Curcumin is a well-known antimicrobial polyphenolic compound derived from Curcuma longa [21]. In this study, we utilized curcumin as an antifungal photosensitizer. As biofilm formation is an important factor in the pathogenesis of C. albicans infection [22], our aim was to determine whether PDT combined with traditional antifungal agents could improve their antimicrobial effect against adherent C. albicans.

\section{Results}

\subsection{Generation of Free Radicals and Singlet Oxygen}

The formation of free radicals and singlet oxygen are the end products of PDT activity. Hence, the production of free radicals by curcumin-PDT was tested primarily by using a scavenger: 1,1-diphenyl-2-picrylhydrazyl (DPPH). As shown in Figure 1a, upon illumination of curcumin, free radicals were generated at about $82 \%$ of the levels scavenged by ascorbic acid-an outstanding antioxidant used here as a positive control. We used 1,3-diphenylisobenzofuran (DPBF) to assay the amount of singlet oxygen formation. As shown in Figure 1b, the amount of singlet oxygen produced by illumination of curcumin was comparable to that produced by the illumination of rose bengal (a well-known photosensitizer and efficient producer of singlet oxygen [23] used here as a positive control).

(a)

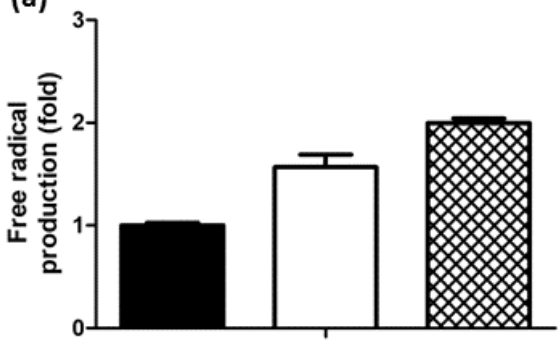

(b)

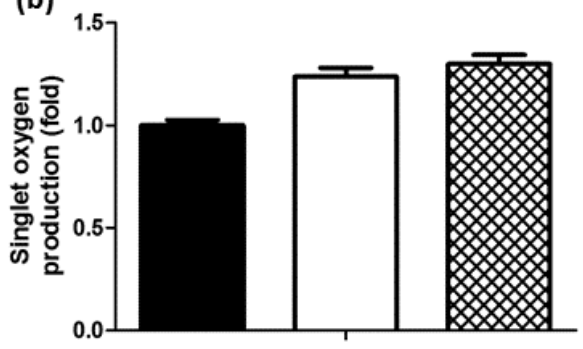

Figure 1. Generation of (a) free radicals and (b) singlet oxygen from curcumin-photodynamic therapy (PDT) detected with 1,1-diphenyl-2-picrylhydrazyl (DPPH) and 1,3-diphenylisobenzofuran (DPBF), respectively. The filled and open columns represent the untreated (control) and curcumin-PDT samples, respectively. The mesh columns represent the positive control: ascorbic acid in (a) and PDT with rose bengal in $(\mathbf{b})$.

\subsection{Viability of C. albicans after Treatment with Antifungal Agent}

The effect of fluconazole-a well-known antifungal agent—on colony formation and viability of C. albicans in suspension is shown in Figure 2. Fluconazole had antifungal activity at $13 \mu \mathrm{M}$ or 
higher, and antifungal activity was maximal at $13 \mu \mathrm{M}$ after $24 \mathrm{~h}$ of treatment. At $48 \mathrm{~h}$ of treatment, no colonies of $C$. albicans were observed in the presence of $208 \mu \mathrm{M}$ fluconazole. The viability of adherent C. albicans was about $40 \%$ even at $208 \mu \mathrm{M}$ after $24 \mathrm{~h}$ of treatment and $\sim 15 \%$ at $208 \mu \mathrm{M}$ after $48 \mathrm{~h}$ of treatment. Moreover, dose dependence was pronounced at higher than $13 \mu \mathrm{M}$ after $48 \mathrm{~h}$ of treatment. Clearly, anticandidal activity of fluconazole is great in C. albicans suspension after prolonged treatment, but greatly weakened by the formation of adherent $C$. albicans biofilms. The weakening of antifungal activity by biofilm formation should be considered in further PDT experiments.

(a)

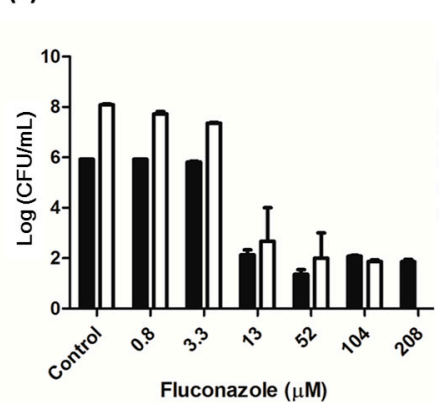

(b)

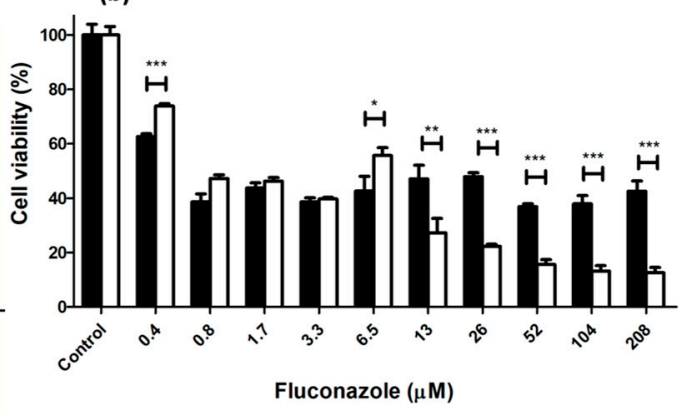

Figure 2. Viability of C. albicans in (a) planktonic culture and (b) adherent culture after treatment with fluconazole. The filled and unfilled columns represent treatments for $24 \mathrm{~h}$ and $48 \mathrm{~h}$, respectively. ${ }^{*} p<0.05,{ }^{* *} p<0.01,{ }^{* * *} p<0.001$.

\subsection{PDT Effect on Planktonic and Adherent C. albicans}

C. albicans grown in both planktonic and adherent cultures was exposed to PDT. As shown in Figure 3a, PDT utilizing $1 \mu \mathrm{M}$ curcumin and $9 \mathrm{~J} / \mathrm{cm}^{2}$ of light was sufficient to decrease the number of planktonic C. albicans colonies by three orders of magnitude. At curcumin concentrations of $5 \mu \mathrm{M}$ or higher, PDT eliminated all C. albicans colonies. Therefore, PDT is very effective when C. albicans is in suspension. This result is very similar to findings from a previous study [24], which used a greater light dose.

(a)

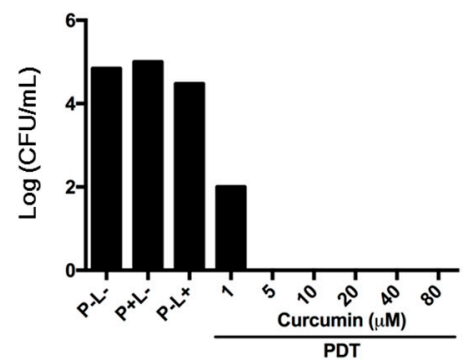

(b)

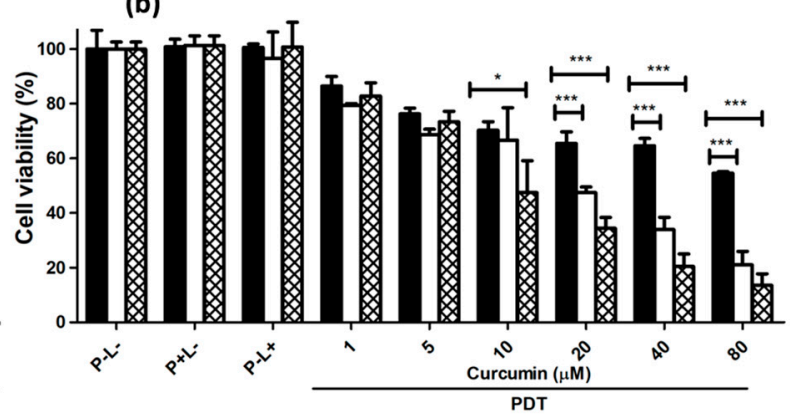

Figure 3. Viability of C. albicans in (a) planktonic culture and (b) adherent culture after PDT treatment. The total illumination time was $30 \mathrm{~min}$. In the experiment of adherent $C$. albicans, illumination was carried out in one (filled), three (unfilled), or six (mesh) cycles. P and L represent photosensitizer and light, respectively. The symbol + indicates that the specific factor was used, and-indicates that the specific factor was not used. ${ }^{*} p<0.05,{ }^{* * *} p<0.001$.

C. albicans in biofilms was more drug-resistant and virulent. As dispersion is an important step in the development of $C$. albicans biofilms, and biofilm formation can greatly reduce the effectiveness of antifungal agents [22,25], we exposed adherent $C$. albicans to PDT. Figure $3 \mathrm{~b}$ shows that the decrease in cell viability after continuous PDT illumination for $30 \mathrm{~min}\left(9 \mathrm{~J} / \mathrm{cm}^{2}\right)$ was weak and less 
in adherent $C$. albicans than in planktonic C. albicans. Intermittent PDT illumination (3-6 periods of illumination over a total of $30 \mathrm{~min}$ ) greatly enhanced the effect, and significantly decreased cell viability. This improvement should be ascribed to the rapid photobleaching of curcumin [24]. PDT utilizing $80 \mu \mathrm{M}$ curcumin and six periods of illumination reduced cell viability to $\sim 15 \%$. However, good antifungal treatment requires the development of a more efficient therapy that totally prevents replication.

\subsection{The Effect of Chemical Therapy Combined with PDT on C. albicans in Adherent Culture}

Neither PDT nor fluconazole treatment is efficient enough to eliminate C. albicans completely in adherent culture. Therefore, sequential treatments with $208 \mu \mathrm{M}$ of fluconazole and PDT utilizing various concentrations of curcumin were tested. As shown in Figure 4, treatment with fluconazole for $24 \mathrm{~h}$ and $48 \mathrm{~h}$ decreased the cell viability to $55 \%$ and $20 \%$, respectively. Fluconazole treatment for $24 \mathrm{~h}$ followed by PDT utilizing $20 \mu \mathrm{M}$ curcumin (or fluconazole-treatment for $48 \mathrm{~h}$ followed by PDT utilizing $10 \mu \mathrm{M}$ curcumin) decreased cell viability to $5 \%$. Obviously, the combination of chemical therapy and PDT greatly promotes the inactivation of C. albicans.

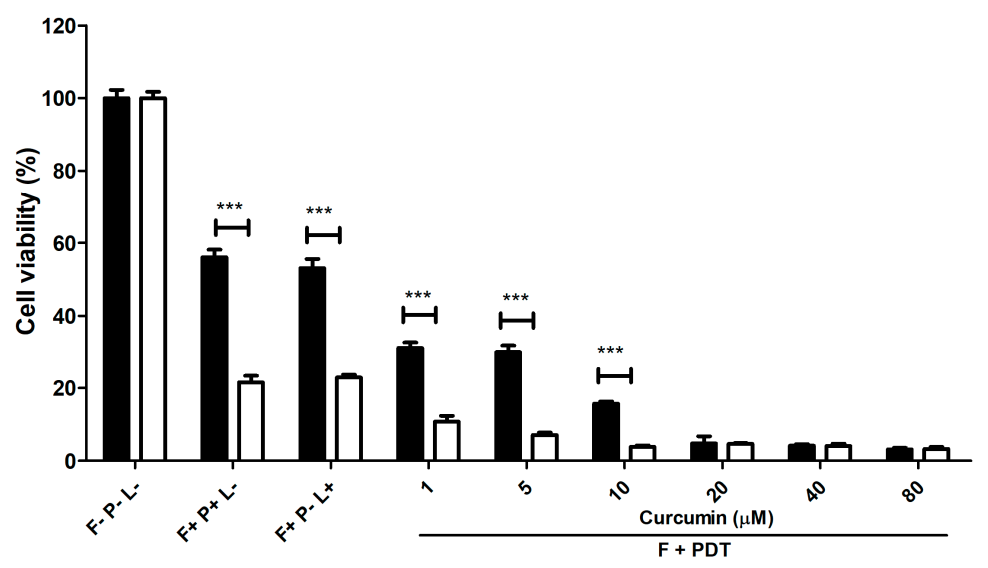

Figure 4. Viability of C. albicans in adherent culture after sequential treatment with fluconazole for $24 \mathrm{~h}$ (filled) or $48 \mathrm{~h}$ (open) and PDT utilizing curcumin. F, P, and L represent fluconazole, photosensitizer, and light, respectively. The symbol + indicates that the specific factor was used, and-indicates that the specific factor was not used. ${ }^{* *} p<0.001$.

\subsection{Cellular Morphology of C. albicans before and after PDT or Chemical Therapy or Both}

Adherent $C$. albicans cells were yeast-like with long pseudohyphae, and formed a biofilm as shown in Figure 5a. Treatment with $208 \mu \mathrm{M}$ fluconazole significantly decreased the presence of yeast-like cells, but not pseudohyphae (Figure 5b). In contrast, PDT removed most of the biofilm mass, but left some yeast-like cells (Figure 5c). The extent of biofilm damage by curcumin-PDT was similar to that by gold nanoparticles (AuNP) treatment [26]. After fluconazole combined with PDT, few yeast-like cells remained and the biofilm was completely eliminated. Most of these yeast-like cells lacked some surface features, as shown in the insert of Figure $5 \mathrm{~d}$. Further examination by scanning electron microscope (SEM) (Figure 6) showed that morphological change in C. albicans after our combination treatment was similar to that after porphyrin PDT as reported previously [27]. These images demonstrate that chemical therapy and PDT can truly eradicate C. albicans cells and disrupt biofilms. 

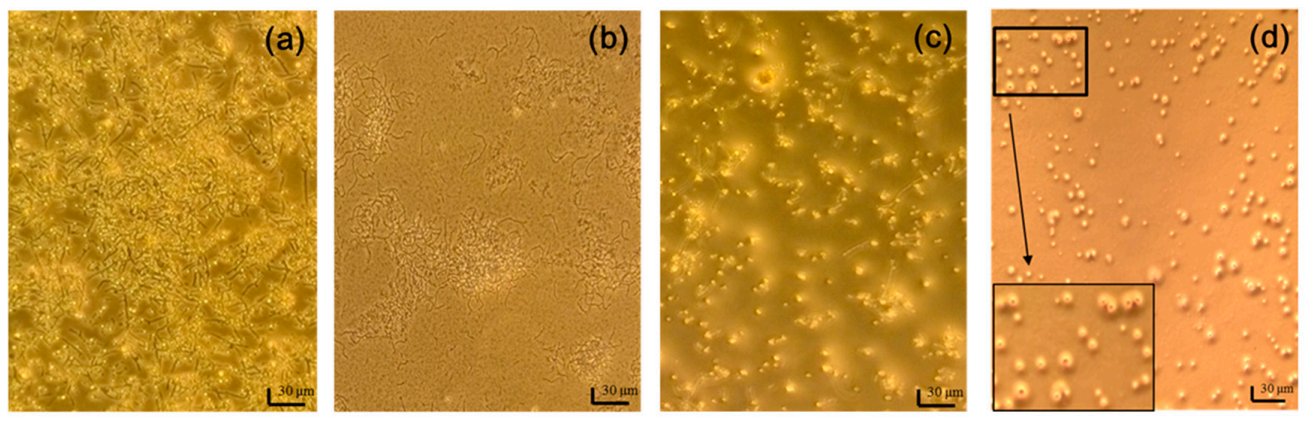

Figure 5. Light images of C. albicans (a) before the treatment, and after the treatments with (b) $208 \mu \mathrm{M}$ fluconazole; (c) PDT; and (d) combination of fluconazole and PDT. The scale bar represents $30 \mu \mathrm{m}$. The surface features in the black box are enlarged for better visualization.
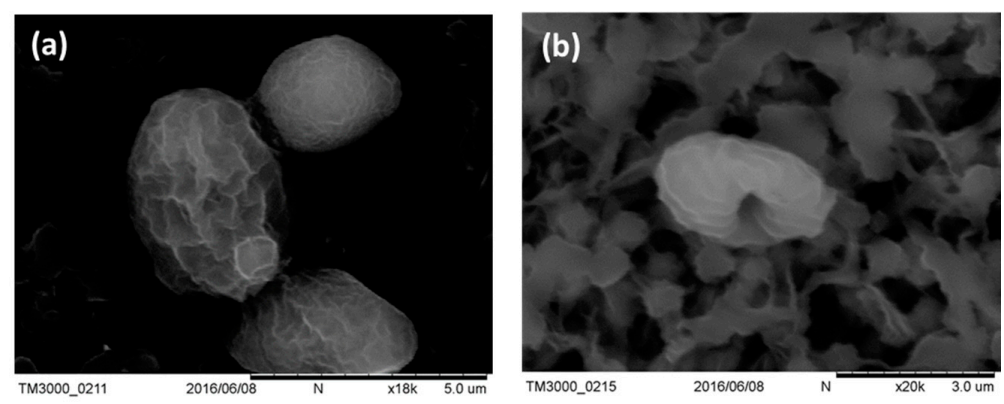

Figure 6. SEM images of C. albicans (a) before and (b) after PDT treatments.

\subsection{PDT-Induced Peroxidation of Membranes}

Fourier transform infrared (FT-IR) spectra (Figure 7) identified the vibrational features of proteins (i.e., amide I, amide II, and amide III at $1900-1600 \mathrm{~cm}^{-1}, 1600-1500 \mathrm{~cm}^{-1}$, and $1400-1300 \mathrm{~cm}^{-1}$, respectively), phospholipids $\left(\mathrm{CH}_{2}\right.$ stretch at $\sim 2900 \mathrm{~cm}^{-1}$, ester $\mathrm{C}=\mathrm{O}$ stretch at $1740 \mathrm{~cm}^{-1}$, phosphodiester asymmetric stretch at $1250 \mathrm{~cm}^{-1}$, and phosphodiester symmetric stretch at $1085 \mathrm{~cm}^{-1}$ ), and cell wall polysaccharides (1200-900 $\mathrm{cm}^{-1}$ ). The band at $1740 \mathrm{~cm}^{-1}$ indicating the ester functional groups of the phospholipids is regarded as an index band for the peroxidation of phospholipids [28]. Sequential treatment with fluconazole and PDT (in contrast to other treatments) resulted in marked increase in the intensity of this index band, as shown in the insert of Figure 7. This result suggests that combination therapy further enhances the peroxidation of phospholipids in C. albicans. The peroxidation of phospholipids might correlate with the change in the surface morphology of $C$. albicans cells.

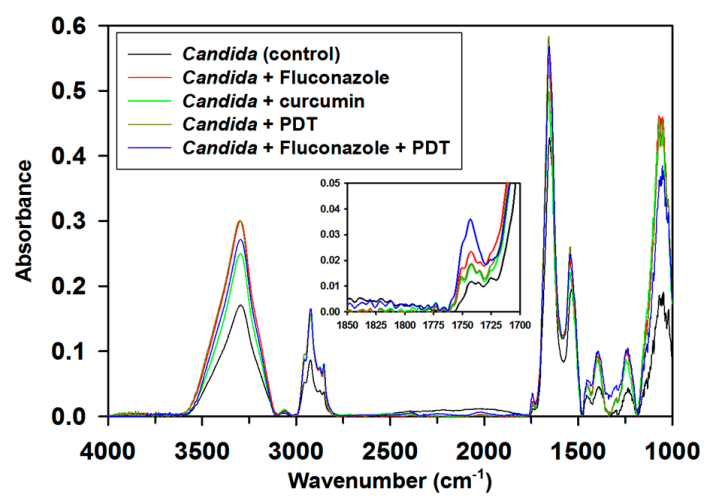

Figure 7. Fourier transform infrared (FT-IR) spectra of C. albicans before the treatment and after the treatments with fluconazole, curcumin, PDT, and combination of fluconazole therapy and PDT. 


\section{Discussion}

Since the early 1980s, fungal infections have been a major problem all over the world, especially in immunocompromised individuals [29] and oral cavities [30]. Alternative therapies have been suggested [14]. One of these, curcumin, has been considered a promising anticandidal drug [31] because of its inhibitory activity and preventive activity on the development of C. albicans biofilms on denture surfaces [32]. Curcumin is effective at sub-millimolar concentration. However, the bioavailability of curcumin is compromised by poor solubility. The healing power of curcumin can be enhanced by increasing its solubility through heating [33], dispersion [34], nanoparticle fabrication [35,36], and metal chelation [37]. In the current work, only micromolar amounts of curcumin are needed, so solubility is not a problem.

For the easy access of light to the oral cavity, photo-associated therapies have been applied to oral fungal infection [15,16]. To further eradicate the fungal pathogens, PDT has been considered [2,17]. For the efficacy of PDT, PDT has been clinically applied to oral cancer and some other cancers [38]. However, the difficulty of antifungal therapy is to overcome biofilms which are critical in virulence and drug-resistance.

Because of the need for new improved antifungal therapies, several combination antifungal therapies have been proposed $[39,40]$. Combining antifungal drugs was recommended to enhance the efficiency of treatments for a variety of infections. However, synergistic benefits have been difficult to achieve due to losses of antifungal activity and clinical efficiency [41]. Moreover, a clinical study of combined antifungal therapies in severely immunocompromised patients found that the mortality rate for invasive fungal infections remains high [42].

Rather than combining two antifungal chemical agents, we combined two antifungal therapies with different mechanisms of action (a chemical therapy and PDT). More than two decades ago, a study found that the phototoxicity of curcumin depends on hydrogen peroxide rather than singlet oxygen [43]. A later study suggested that the curcumin phototoxicity mechanism involves both type I $\left(\mathrm{O}_{2}\right.$ and $\mathrm{H}_{2} \mathrm{O}_{2}$ formation) and type II (singlet oxygen) reactions [44]. In the present study, the generation of free radicals and singlet oxygen were detected by the DPPH and DPBF assays, respectively. DPPH can trap various radicals including singlet oxygen, while DPBF specifically identifies singlet oxygen. Similar to most PDT mechanisms [1], the mechanism of our PDT against C. albicans should rely on singlet oxygen as the major reactive oxygen species (ROS), but we cannot rule out the toxicity of other radical species.

PDT has been used against a variety of microbial pathogens [45]. In a previous study, antimicrobial PSs were synthesized to carried out PDT under high illumination energy $\left(40 \mathrm{~J} / \mathrm{cm}^{2}\right)$, but the effect on the biofilms was not identified [46]. Two studies have reported the effectiveness of a PDT with $40 \mu \mathrm{M}$ curcumin and blue light against C. albicans [24,47]. In a murine model, PDT utilizing $80 \mu \mathrm{M}$ of curcumin and $37.5 \mathrm{~J} / \mathrm{cm}^{2}$ of blue light significantly decreased the viability of C. albicans [44]. Combined treatment with photodynamic and chemical therapies has been applied to cancer treatments [48,49], but has not been applied to fungal infections. In the current work, fluconazole was a very efficient inhibitor of $C$. albicans replication. However, virulence caused by biofilm formation made eradicating biofilms an important issue. In our study, $5 \mu \mathrm{M}$ curcumin and $9 \mathrm{~J} / \mathrm{cm}^{2}$ of blue light were sufficient to eradicate biofilms. Thus, combining fluconazole with PDT can both inhibit C. albicans replication and eradicate biofilms completely. Notably, the eradication of biofilms is to completely inhibit the virulence of the fungal pathogens and to prevent drug resistance in the chemical therapy.

\section{Materials and Methods}

\subsection{Measurement of Free Radicals and ${ }^{1} \mathrm{O}_{2}$ Generation}

The amount of free radicals generated after illumination in the presence of curcumin was determined based on the scavenging activity of DPPH. Equal volumes of $25 \mu \mathrm{M} \mathrm{DPPH}$ and $0.5 \mu \mathrm{M}$ of curcumin were mixed in ethanol solution and subsequently illuminated to activate the redox 
reaction (see PDT experiments for details). In the positive control, curcumin was replaced by an equal concentration of ascorbic acid (no illumination). After $30 \mathrm{~min}$ of scavenging reaction, the decrease in $\mathrm{DPPH}$ absorbance was measured at $517 \mathrm{~nm}$.

The amount of singlet oxygen generated after illumination was determined by DPBF. Equal volumes of $10 \mu \mathrm{M}$ DPBF and $1 \mu \mathrm{M}$ curcumin mixed in ethanol solution were used for fluorescence measurements and PDT experiments. The excitation and monitored emission wavelengths were $403 \mathrm{~nm}$ and $450 \mathrm{~nm}$, respectively. Comparatively, rose bengal-a well-known photosensitizer that produces large amounts of singlet oxygen—was used as a positive control.

\subsection{Culture of Planktonic C. albicans and Planktonic Cell Viability}

C. albicans (ATCC 90029) suspensions $\left(3 \times 10^{8}\right.$ cells $/ \mathrm{mL}$ ) were cultured in glass tubes at $37^{\circ} \mathrm{C}$. To test fluconazole as the chemical therapy, it was added to $C$. albicans in TGC medium and incubated at $37^{\circ} \mathrm{C}$ for $24 \mathrm{~h}$ or $48 \mathrm{~h}$. To determine cell viability, aliquots of 100 -fold $(10,000$-fold dilution for the control) serial dilutions of each sample were seeded on chocolate agar plates. All plates were aerobically incubated at $37^{\circ} \mathrm{C}$ for $18 \mathrm{~h}$, and the number of colony forming units per milliliter $(\mathrm{CFU} / \mathrm{mL})$ was calculated from the plate counts. According to the National Committee for Clinical Laboratory Standards, the minimum inhibitory concentration of fluconazole for C. albicans is $208 \mu \mathrm{M}(64 \mathrm{mg} / \mathrm{L})$ [50]. In this study, the fluconazole concentration was lower than $208 \mu \mathrm{M}$.

\subsection{Culture of Adherent C. albicans and Adherent Cell Viability}

Primarily, $100 \mu \mathrm{L}$ of $C$. albicans suspension was transferred into a 96-well culture plate at concentration of $3 \times 10^{8}$ cells $/ \mathrm{mL}$ and incubated at $37^{\circ} \mathrm{C}$ in an orbital shaker at $75 \mathrm{rpm}$ for $1.5 \mathrm{~h}$. Subsequently, samples were washed twice with $150 \mu \mathrm{L}$ of phosphate-buffered saline (PBS) to remove suspended cells. To allow C. albicans to form a biofilm, $150 \mu \mathrm{L}$ of fresh TGC medium was added for further incubation at $37^{\circ} \mathrm{C}$ for $18 \mathrm{~h}$ with shaking at $75 \mathrm{rpm}$. Afterwards, the samples were carefully washed twice with $200 \mu \mathrm{L}$ of PBS to remove the remaining nonadherent cells.

The cell viability assay using water soluble tetrazolium salt WST-1 (2-(4-Iodophenyl)-3(4-nitrophenyl)-5-(2,4-disulfophenyl)-2H-tetrazolium) was used to measure the viability of adherent C. albicans cells. The addition of $100 \mu \mathrm{L}$ of medium containing $5 \mu \mathrm{L}$ of WST-1 was followed by incubation for $4 \mathrm{~h}$ at $37^{\circ} \mathrm{C}$ in the dark and measurement of formazan absorbance at $450 \mathrm{~nm}$ in an ELISA reader. For statistical analysis, a $t$-test was performed. The reported values are the mean values of three replicates. Statistical significance was indicated at ${ }^{*}<<0.05,{ }^{* *} p<0.01$, or ${ }^{* * *} p<0.001$, depending on the experiments.

\subsection{PDT Experiments}

PDT experiments were carried out by illuminating curcumin-treated $C$. albicans using a home-made device consisting of an array of 24 blue LEDs (peak emission wavelength at $430 \mathrm{~nm}$ ). The accumulated photoenergy after $30 \mathrm{~min}$ of illumination was $9 \mathrm{~J} / \mathrm{cm}^{2}$. Curcumin solutions were added to $C$. albicans suspensions to reach final curcumin concentrations of $1,5,10,20,40$, and $80 \mu \mathrm{M}$. One $\mathrm{mL}$ of the $C$. albicans-curcumin mixture was transferred to a 12-well plate and incubated in the dark for $20 \mathrm{~min}$. Subsequent illumination activated the PDT. In experiments combining PDT with chemical therapy, C. albicans was treated with $208 \mu \mathrm{M}$ fluconazole prior to the PDT experiments.

\subsection{Scanning Electron Microscopy (SEM)}

C. albicans samples were collected on $0.45 \mu \mathrm{m}$ filter paper, fixed with $2.5 \%$ glutaraldehyde for $1 \mathrm{~h}$, dehydrated by washing with a series of ethanol solutions ( $25 \%, 50 \%, 75 \%$, and $95 \%$ for $5 \mathrm{~min}$, and $99.5 \%$ for $1 \mathrm{~h}$ ), and finally dehydrated by critical point drying with carbon dioxide. After coating with gold, the samples were imaged under an electron microscope (Hitachi TM3000, Hitachi, Tokyo, Japan). 


\subsection{FT-IR Microspectroscopy of C. albicans after PDT and/or Chemical Treatment}

The FT-IR spectroscopy of single cells was performed by using a FTIR spectrometer (Nicolet 6700, Thermo-Fisher Scientific, Madison, WI, USA) with $4 \mathrm{~cm}^{-1}$ spectral resolution and $900-3600 \mathrm{~cm}^{-1}$ scanning range. For each sample, 20 spectra in different fields $(20 \mu \mathrm{m} \times 20 \mu \mathrm{m})$ were collected with a confocal infrared microscope (Nicolet Continuum; Thermo-Fisher Scientific, Madison, WI, USA) at infrared microspectroscopy endstation BL14A1 of National Synchrotron Research Radiation Center. Each representative spectrum is an average of 20 spectra.

\section{Conclusions}

C. albicans is the most common superficial fungal infection in humans [51,52]. An effective therapy to kill the cells and reduce their biofilm-associated virulence is required. Fluconazole greatly eliminates the yeast form, but not the biofilms, whereas curcumin-PDT has the opposite effect. Therefore, the combination of fluconazole treatment and curcumin-PDT to fully eradicate the growth and virulence of $C$. albicans has clinical potential. Similarly, the combination of chemical therapy and PDT could also be helpful in fighting other pathogens.

Acknowledgments: We are grateful to Dalin Tzu Chi Hospital, Buddhist Tzu Chi Medical Foundation for financial support (DTCRD105-E-18) and National Synchrotron Radiation Research Center for beam time and facilities.

Author Contributions: Yi-Hsuan Hsieh initiated experiments of C. albicans; Jun-Hui Zhang, Wen-Ching Chuang, Kun-Hua Yu and Xian-Bin Huang performed experiments; Yao-Chang Lee guided the FTIR experimental strategy and assisted data analysis; Cheng-I Lee led the project and wrote the manuscript.

Conflicts of Interest: The authors declare no conflict of interest.

$\begin{array}{ll}\text { Abbreviations } \\ \text { PDT } & \text { Photodynamic therapy } \\ \text { PS } & \text { Photosensitizer } \\ { }^{1} \mathrm{O}_{2} & \text { Singlet oxygen } \\ { }^{5-A L A} & \text { 5-aminolevulinic acid } \\ \text { DPPH } & \text { 1,1-diphenyl-2-picrylhydrazyl } \\ \text { DPBF } & \text { 1,3-diphenylisobenzofuran } \\ \text { CFU } & \text { Colony forming units } \\ \text { SEM } & \text { Scanning electron microscopy } \\ \text { FT-IR } & \text { Fourier transform infrared }\end{array}$

\section{References}

1. Dougherty, T.J.; Gomer, C.J.; Henderson, B.W.; Jori, G.; Kessel, D.; Korbelik, M.; Moan, J.; Peng, Q. Photodynamic therapy. J. Natl. Cancer Inst. 1998, 90, 889-905. [CrossRef] [PubMed]

2. Hamblin, M.R.; Hasan, T. Photodynamic therapy: A new antimicrobial approach to infectious disease? Photochem. Photobiol. Sci. 2004, 3, 436-450. [CrossRef] [PubMed]

3. Bennett, R.J. The parasexual lifestyle of Candida albicans. Curr. Opin. Microbiol. 2015, 28, 10-17. [CrossRef] [PubMed]

4. Schelenz, S. Management of candidiasis in the intensive care unit. J. Antimicrob. Chemother. 2008, 61, i31-i34. [CrossRef] [PubMed]

5. Williams, D.; Lewis, M. Pathogenesis and treatment of oral candidosis. J. Oral Microbiol. 2011, 3, 5771. [CrossRef] [PubMed]

6. Rocha, C.R.; Schroppel, K.; Harcus, D.; Marcil, A.; Dignard, D.; Taylor, B.N.; Thomas, D.Y.; Whiteway, M.; Leberer, E. Signaling through adenylyl cyclase is essential for hyphal growth and virulence in the pathogenic fungus Candida albicans. Mol. Biol. Cell 2001, 12, 3631-3643. [CrossRef] [PubMed]

7. Bondaryk, M.; Kurzatkowski, W.; Staniszewska, M. Antifungal agents commonly used in the superficial and mucosal candidiasis treatment: Mode of action and resistance development. Postepy Dermatol. Alergol. 2013, 30, 293-301. [CrossRef] [PubMed] 
8. Hawser, S.P.; Douglas, L.J. Resistance of Candida albicans biofilms to antifungal agents in vitro. Antimicrob. Agents Chemother. 1995, 39, 2128-2131. [CrossRef] [PubMed]

9. Silva, S.; Henriques, M.; Martins, A.; Oliveira, R.; Williams, D.; Azeredo, J. Biofilms of non-Candida albicans Candida species: Quantification, structure and matrix composition. Med. Mycol. 2009, 47, 681-689. [CrossRef] [PubMed]

10. Debruyne, D.; Ryckelynck, J.P. Clinical pharmacokinetics of fluconazole. Clin. Pharmacokinet. 1993, 24, $10-27$. [CrossRef] [PubMed]

11. Lee, B.E.; Feinberg, M.; Abraham, J.J.; Murthy, A.R. Congenital malformations in an infant born to a woman treated with fluconazole. Pediatr. Infect. Dis. J. 1992, 11, 1062-1064. [PubMed]

12. Pursley, T.J.; Blomquist, I.K.; Abraham, J.; Andersen, H.F.; Bartley, J.A. Fluconazole-induced congenital anomalies in three infants. Clin. Infect. Dis. 1996, 22, 336-340. [CrossRef] [PubMed]

13. Lopez-Rangel, E.; Van Allen, M.I. Prenatal exposure to fluconazole: An identifiable dysmorphic phenotype. Birth Defects Res. A 2005, 73, 919-923. [CrossRef] [PubMed]

14. Martins, N.; Ferreira, I.C.; Barros, L.; Silva, S.; Henriques, M. Candidiasis: Predisposing factors, prevention, diagnosis and alternative treatment. Mycopathologia 2014, 177, 223-240. [CrossRef] [PubMed]

15. Al-Maweri, S.A.; Javed, F.; Kalakonda, B.; AlAizari, N.A.; Al-Soneidar, W.; Al-Akwa, A. Efficacy of low level laser therapy in the treatment of burning mouth syndrome: A systematic review. Photodiagn. Photodyn. Ther. 2017, 17, 188-193. [CrossRef] [PubMed]

16. Dos Santos Lde, F.; de Andrade, S.C.; Nogueira, G.E.; Leao, J.C.; de Freitas, P.M. Phototherapy on the Treatment of Burning Mouth Syndrome: A Prospective Analysis of 20 Cases. Photochem. Photobiol. 2015, 91, 1231-1236. [CrossRef] [PubMed]

17. Rajesh, S.; Koshi, E.; Philip, K.; Mohan, A. Antimicrobial photodynamic therapy: An overview. J. Indian Soc. Periodontol. 2011, 15, 323-327. [PubMed]

18. Dahl, T.A.; Midden, W.R.; Neckers, D.C. Comparison of photodynamic action by Rose Bengal in Gram-positive and Gram-negative bacteria. Photochem. Photobiol. 1988, 48, 607-612. [CrossRef] [PubMed]

19. Shi, H.; Li, J.; Zhang, H.; Zhang, J.; Sun, H. Effect of 5-aminolevulinic acid photodynamic therapy on Candida albicans biofilms: An in vitro study. Photodiagn. Photodyn. Ther. 2016, 15, 40-45. [CrossRef] [PubMed]

20. Tabery, H.M. Toxic effect of rose bengal dye on the living human corneal epithelium. Acta Ophthalmol. Scand. 1998, 76, 142-145. [CrossRef] [PubMed]

21. Moghadamtousi, S.Z.; Kadir, H.A.; Hassandarvish, P.; Tajik, H.; Abubakar, S.; Zandi, K. A review on antibacterial, antiviral, and antifungal activity of curcumin. Biomed. Res. Int. 2014, 2014, 186864. [PubMed]

22. Uppuluri, P.; Chaturvedi, A.K.; Srinivasan, A.; Banerjee, M.; Ramasubramaniam, A.K.; Kohler, J.R.; Kadosh, D.; Lopez-Ribot, J.L. Dispersion as an important step in the Candida albicans biofilm developmental cycle. PLoS Pathog. 2010, 6, e1000828. [CrossRef] [PubMed]

23. DeRosa, M.C.; Crutchley, R.J. Photosensitized singlet oxygen and its applications. Coord. Chem. Rev. 2002, 233, 351-371. [CrossRef]

24. Dovigo, L.N.; Pavarina, A.C.; Ribeiro, A.P.; Brunetti, I.L.; Costa, C.A.; Jacomassi, D.P.; Bagnato, V.S.; Kurachi, C. Investigation of the photodynamic effects of curcumin against Candida albicans. Photochem. Photobiol. 2011, 87, 895-903. [CrossRef] [PubMed]

25. Noble, S.M.; Gianetti, B.A.; Witchley, J.N. Candida albicans cell-type switching and functional plasticity in the mammalian host. Nat. Rev. Microbiol. 2017, 15, 96-108. [CrossRef] [PubMed]

26. Yu, Q.; Li, J.; Zhang, Y.; Wang, Y.; Liu, L.; Li, M. Inhibition of gold nanoparticles (AuNPs) on pathogenic biofilm formation and invasion to host cells. Sci. Rep. 2016, 6, 26667. [CrossRef] [PubMed]

27. Lambrechts, S.A.; Aalders, M.C.; Van Marle, J. Mechanistic study of the photodynamic inactivation of Candida albicans by a cationic porphyrin. Antimicrob. Agents Chemother. 2005, 49, 2026-2034. [CrossRef] [PubMed]

28. Oleszko, A.; Olsztynska-Janus, S.; Walski, T.; Grzeszczuk-Kuc, K.; Bujok, J.; Galecka, K.; Czerski, A.; Witkiewicz, W.; Komorowska, M. Application of FTIR-ATR Spectroscopy to Determine the Extent of Lipid Peroxidation in Plasma during Haemodialysis. Biomed. Res. Int. 2015, 2015, 245607. [CrossRef] [PubMed]

29. Pfaller, M.A.; Diekema, D.J. Epidemiology of invasive candidiasis: A persistent public health problem. Clin. Microbiol. Rev. 2007, 20, 133-163. [CrossRef] [PubMed]

30. Salerno, C.; Di Stasio, D.; Petruzzi, M.; Lauritano, D.; Gentile, E.; Guida, A.; Maio, C.; Tammaro, M.; Serpico, R.; Lucchese, A. An overview of burning mouth syndrome. Front. Microbiol. 2016, 8, 213-218. 
31. Neelofar, K.; Shreaz, S.; Rimple, B.; Muralidhar, S.; Nikhat, M.; Khan, L.A. Curcumin as a promising anticandidal of clinical interest. Can. J. Microbiol. 2011, 57, 204-210. [CrossRef] [PubMed]

32. Alalwan, H.; Rajendran, R.; Lappin, D.F.; Combet, E.; Shahzad, M.; Robertson, D.; Nile, C.J.; Williams, C.; Ramage, G. The Anti-Adhesive Effect of Curcumin on Candida albicans Biofilms on Denture Materials. Front. Microbiol. 2017, 8, 659. [CrossRef] [PubMed]

33. Kurien, B.T.; Singh, A.; Matsumoto, H.; Scofield, R.H. Improving the solubility and pharmacological efficacy of curcumin by heat treatment. Assay Drug Dev. Technol. 2007, 5, 567-576. [CrossRef] [PubMed]

34. Wan, S.; Sun, Y.; Qi, X.; Tan, F. Improved bioavailability of poorly water-soluble drug curcumin in cellulose acetate solid dispersion. AAPS PharmSciTech 2012, 13, 159-166. [CrossRef] [PubMed]

35. Basniwal, R.K.; Buttar, H.S.; Jain, V.K.; Jain, N. Curcumin nanoparticles: Preparation, characterization, and antimicrobial study. J. Agric. Food Chem. 2011, 59, 2056-2061.

36. Yallapu, M.M.; Jaggi, M.; Chauhan, S.C. Curcumin nanoformulations: A future nanomedicine for cancer. Drug Discov. Today 2012, 17, 71-80. [CrossRef] [PubMed]

37. Wanninger, S.; Lorenz, V.; Subhan, A.; Edelmann, F.T. Metal complexes of curcumin—Synthetic strategies, structures and medicinal applications. Chem. Soc. Rev. 2015, 44, 4986-5002. [CrossRef] [PubMed]

38. Agostinis, P.; Berg, K.; Cengel, K.A.; Foster, T.H.; Girotti, A.W.; Gollnick, S.O.; Hahn, S.M.; Hamblin, M.R.; Juzeniene, A.; Kessel, D.; et al. Photodynamic therapy of cancer: An update. CA Cancer J. Clin. 2011, 61, 250-281. [CrossRef] [PubMed]

39. Marr, K. Combination antifungal therapy: Where are we now, and where are we going? Oncology 2004, 18, 24-29. [PubMed]

40. Johnson, M.D.; MacDougall, C.; Ostrosky-Zeichner, L.; Perfect, J.R.; Rex, J.H. Combination antifungal therapy. Antimicrob. Agents Chemother. 2004, 48, 693-715. [CrossRef] [PubMed]

41. Lewis, R.E.; Kontoyiannis, D.P. Rationale for combination antifungal therapy. Pharmacotherapy 2001, 21, 149S-164S. [CrossRef] [PubMed]

42. Chamilos, G.; Kontoyiannis, D.P. The rationale of combination antifungal therapy in severely immunocompromised patients: Empiricism versus evidence-based medicine. Curr. Opin. Infect. Dis. 2006, 19, 380-385. [CrossRef] [PubMed]

43. Dahl, T.A.; McGowan, W.M.; Shand, M.A.; Srinivasan, V.S. Photokilling of bacteria by the natural dye curcumin. Arch. Microbiol. 1989, 151, 183-185. [CrossRef] [PubMed]

44. Dovigo, L.N.; Carmello, J.C.; de Souza Costa, C.A.; Vergani, C.E.; Brunetti, I.L.; Bagnato, V.S.; Pavarina, A.C. Curcumin-mediated photodynamic inactivation of Candida albicans in a murine model of oral candidiasis. Med. Mycol. 2013, 51, 243-251. [CrossRef] [PubMed]

45. Jori, G.; Fabris, C.; Soncin, M.; Ferro, S.; Coppellotti, O.; Dei, D.; Fantetti, L.; Chiti, G.; Roncucci, G. Photodynamic therapy in the treatment of microbial infections: Basic principles and perspective applications. Laser Surg. Med. 2006, 38, 468-481. [CrossRef] [PubMed]

46. Mizuno, K.; Zhiyentayev, T.; Huang, L.; Khalil, S.; Nasim, F.; Tegos, G.P.; Gali, H.; Jahnke, A.; Wharton, T.; Hamblin, M.R. Antimicrobial Photodynamic Therapy with Functionalized Fullerenes: Quantitative Structure-activity Relationships. J. Nanomed. Nanotechnol. 2011, 2, 1-9. [CrossRef] [PubMed]

47. Dovigo, L.N.; Pavarina, A.C.; Carmello, J.C.; Machado, A.L.; Brunetti, I.L.; Bagnato, V.S. Susceptibility of clinical isolates of Candida to photodynamic effects of curcumin. Laser Surg. Med. 2011, 43, 927-934. [CrossRef] [PubMed]

48. Seshadri, M.; Spernyak, J.A.; Mazurchuk, R.; Camacho, S.H.; Oseroff, A.R.; Cheney, R.T.; Bellnier, D.A. Tumor vascular response to photodynamic therapy and the antivascular agent 5,6-dimethylxanthenone-4-acetic acid: Implications for combination therapy. Clin. Cancer Res. 2005, 11, 4241-4250. [CrossRef] [PubMed]

49. Canti, G.; Nicolin, A.; Cubeddu, R.; Taroni, P.; Bandieramonte, G.; Valentini, G. Antitumor efficacy of the combination of photodynamic therapy and chemotherapy in murine tumors. Cancer Lett. 1998, 125, $39-44$. [CrossRef]

50. National Committee of Clinical Laboratory Standards. Reference Method for Broth Dilution Antifungal Susceptibility Testing of Yeasts; Approved Standard M27-A; National Committee for Clinical Laboratory Standards: Wayne, PA, USA, 1997. 
51. Wisplinghoff, H.; Bischoff, T.; Tallent, S.M.; Seifert, H.; Wenzel, R.P.; Edmond, M.B. Nosocomial bloodstream infections in US hospitals: Analysis of 24,179 cases from a prospective nationwide surveillance study. Clin. Infect. Dis. 2004, 39, 309-317. [CrossRef] [PubMed]

52. Mayer, F.L.; Wilson, D.; Hube, B. Candida albicans pathogenicity mechanisms. Virulence 2013, 4, 119-128. [CrossRef] [PubMed] 